\title{
USING R PACKAGES ‘TMAP’, 'RASTER’ AND ‘GGMAP’ FOR CARTOGRAPHIC VISUALIZATION: AN EXAMPLE OF DEM-BASED TERRAIN MODELLING OF ITALY, APENNINE PENINSULA
}

\author{
Polina Lemenkova ${ }^{* 1}$
}

"Schmidt Institute of Physics of the Earth, Russian Academy of Sciences, Department of Natural Disasters, Moscow, Russian Federation

\begin{abstract}
The main purpose of this article is to present the use of $\mathrm{R}$ programming language in cartographic visualization demonstrating using machine learning methods in geographic education. Current trends in education technologies are largely influenced by the possibilities of distance-learning, e-learning and selflearning. In view of this, the main tendencies in modern geographic education include active use of open source GIS and publicly available free geospatial datasets that can be used by students for cartographic exercises, data visualization and mapping, both at intermediate and advanced levels. This paper contributes to the development of these methods and is fully based on the datasets and tools available for every student: the R programming language and the free open source datasets. The case study demonstrated in this paper show the examples of both physical geographic mapping (geomorphology) and socio-economic geography (regional mapping) which can be used in the classes and in self-learning. The objective of this research includes geomorphological modelling of the terrain relief in Italy and regional mapping. The data include DEM SRTM90 and datasets on regional borders of Italy embedded in R packages 'maps' and 'mapdata'. Modelling references to the characteristics of slope, aspect, hillshade and elevation, their visualization using R packages: 'raster' and 'tmap'. Regional mapping of Italy was made using main package 'ggmap' with the 'ggplot2' as a wrapper. The results present five

\footnotetext{
${ }^{1}$ Corresponding author: P. Lemenkova, Schmidt Institute of Physics of the Earth, Russian Academy of Sciences. Department of Natural Disasters. Laboratory of Regional Geophysics and Natural Disasters. Bolshaya Gruzinskaya St, 10, Bld. 1, Moscow, Russian Federation.

e-mail: pauline.lemenkova@gmail.com
} 
thematic maps (slope, aspect, hillshade, elevation and regions of Italy) created in $\mathrm{R}$ language. Traditionally used in statistical analysis, $\mathrm{R}$ is less known as a perfect tool in geographic education. This paper contributes to the development of methods in geographic education by presenting new technologies of the machine learning methods of mapping.

Key words: R, script, programming language, cartography, data analysis, DEM.

\section{Introduction}

The main tendencies in geographic education have been influenced by the open source GIS and publicly available free geospatial datasets (both raster and vector formats) that can be used by students for cartographic exercises. In view of the increased demand on the distance-based self learning creates the need for the open source programs in educational technologies. The development of the open source geoinformation technologies in cartographic methods recently made significant progress due to such excellent open source GIS as cartographic toolsets as QGIS, Generic Mapping Tools (Lemenkova, 2020a, 2020b), ILWIS GIS (Lemenkova, 2013), IDRISI GIS (Da Serra Costa et al. 1996; Lemenkova, 2014), GRASS GIS (Alvioli et al. 2020; Lemenkova, 2020c), SAGA GIS (Vacca et al. 2014; Lemenkova, 2020d), largely used in geoscience research. Besides the software, a variety of open source data exist available from various sources: Landsat TM and Sentinel-2A satellite images by the USGS, widely used in geoscience (Allevato et al. 2019; Lemenkova, 2015), Google Earth aerial imagery, Digital Chart of the World (DCW), raster topographic datasets: elevation DEMs, such as SRTM15, GEBCO, ETOPO1, GLOBE, to mention a few. Therefore, using available sources of such geographic information, students can get free of charge datasets, vector layers, raster grids and satellite images that are constantly updated.

Once the data are captured, another question arises: which software to use? Leaving apart the mentioned above GIS applications, this paper focuses on the presenting non-trivial method of geographic data visualization in geographic education: the use of free and open source $\mathrm{R}$ programming language (R Core Team, 2020) for cartographic visualization by students. In particular, its specific libraries (also known as packages) used in this paper are the following ones: ggmap (Kahle \& Wickham, 2013), maps, mapdata, sp, raster, tmap. These libraries are specifically tailored for cartographic visualization. In turn, they require the dependent packages, used for auxiliary data manipulation: ncdf4, RColorBrewer (Brewer et al. 2003; Neuwirth, 2014), sp (package for processing spatial data) and sf (Pebesma, 2017). 
For a long time, GIS was the only possibility to create maps, while the R language and its libraries was used to obtain the statistical information for modelling, assessment and graphical visualization of the tabular datasets (Lemenkova, 2019a). However, a variety of $R$ packages nowadays presents new opportunities of using machine learning approaches in geographic education. Using $\mathrm{R}$, quantitative and qualitative types of data stored in the tables as 'data.frame' are processed using a variety of statistical methods, and visualized as plots. However, it is also possible to use R not only for statistical analysis but in geographic mapping, which is much less known and popular comparing to GIS spatial applications in geographic and environmental data analysis (e.g. Allen et al. 1999; Suetova et al. 2005; Klaučo et al. 2013a, 2013b; Lemenkova, 2011). Specifically, $\mathrm{R}$ can be used for plotting traditional maps, and receiving information from the more complex spatial geomorphological analysis (slope, aspect, elevation, hillshade). The geomorphometry is widely used and applied in landform mapping (Evans, 2012) which makes R especially useful in landscape studies.

$R$ has a relatively straightforward syntax with a variety of packages that can be installed and uploaded additionally, via the RStudio (RStudio Team, 2017) and package installer by R. For instance, using a module 'tm_graticules' can be used for adding grid graticule and its additional elements (ticks, lines, labels) on maps and plotting them in a specific way (e.g. rotated, colored, using enlarged fonts, etc). R package 'tmap' can also be used for creating complex cartographic layouts with legends. Applying various color palettes can be done via the package 'RColorBrewer', adding cartographic elements (legends, multi-level annotations, scale bars, directional compass). The use of 'ncdf4' package is an additional condition for manipulating with various raster formats. The 'tmap' gives an opportunity to create classic maps in R, while 'raster' packages can be used for geomorphological analysis (calculation of slope, aspect, hillshade and elevation) from the SRTM 90 m datasets available by the getData() function, which gives an access to the elevation data.

The research objective of this work concerns the following issues: 1) Introduce application of the cartographic functionality of $R$ available in the packages 'tmap' (Tennekes, 2018), 'raster' (Hijmans, 2017), 'maps' (Becker et al. 2013), 'mapdata'. 2) Perform geomorphometric analysis of the Apennine Peninsula by 'raster' package with a visualized screenshot of $\mathrm{R}$ script and final layout output. 3) Present technical detailes of the packages as a visualized codes. 4) Apply 'tmap' and 'ggmap' packages for cartographic visualization. The presented topics should cover a large need of the cartographic issues in geographic education, since both $\mathrm{R}$ and data used in this study are open source and can be used in distance-based learning and geographic education. 


\section{Study Area}

This paper focuses on mapping the Italy with two specific examples of geographic mapping: physical geographic and socio-economic (regional): 1) topographic mapping based on DEM, using 'tmap' and "raster packages as the main tools. This includes calculation and visualization of slope, aspect, hillshade and elevation using SRTM90 dataset; 2) regional mapping of country borders using 'ggmap' packages as the main tool, 'maps' package (Becker et al. 2013) and a 'mapdata' as its supplement, providing access to larger and higher-resolution databases. Italy has been selected as the country with one of the most representative countries on geomorphology and hilly relief, suitable for terrain analysis.

The landscapes on the Apennine Peninsula evolve under the control of a variety of factors which should be briefly mentioned. Among the most important ones are complex geological setting, fault system, tectonic deformations creating well-exposed faults in the region (Roberts \& Michetti). For instance, the uplift occurring during Middle and Upper Pleistocene caused formation of the low relief. The uplift of the Northern Apennine mountain chain shaped the fluvio-lacustrine landforms in Italy (Bartolini, 2003). Landscape formation is also affected by vegetation, climate dynamics and sedimentation (Bertotti et al. 1997; Guido et al. 2020). Surface topography reflects landscape evolution, geomorphic processes, which in turn are influenced by the tectonic events (Bull, 2007), seismicity and earthquakes in faulted mountain fronts affecting river network of the basins and highs. Other factors sculpturing landforms include formation of the orogenic belts, morphotectonics of the Pliocene-Pleistocene regional uplifts affecting topography of the Central-Northern Apennines and Po Basin (Centamore, Nisio, 2003; Zuffetti \& Bersezio, 2020) and tectonically active L'Aquila Basin (Cosentino et al. 2017).

As a result, modern topography of the Apennines reflects the interactions between crustal-mantle and surface processes since the Late Miocene which affect the geomorphology of the peninsula in course of geologic, and tectonic-morphologic evolution of the orogenic belt in the Apennines (Bartolini et al. 2003). The formed landscapes record the sequence of geomorphic evolutionary steps, as well as the spatial-temporal relations between the active geological processes. As a result, the relief of Italy is highly uneven and varies regionally within the country, which makes it suitable for topographic visualization, already presented in existing papers on terrain DEM analysis of the selected landscapes in Italy (Tarquini et al. 2007; Ascione et al. 2008; Geurts et al. 2020; Gemelli et al. 2011). 
Using $R$ packages 'tmap', 'raster' and 'ggmap' for cartographic visualization: an example of DEM-based terrain modelling of Italy, Apennine peninsula

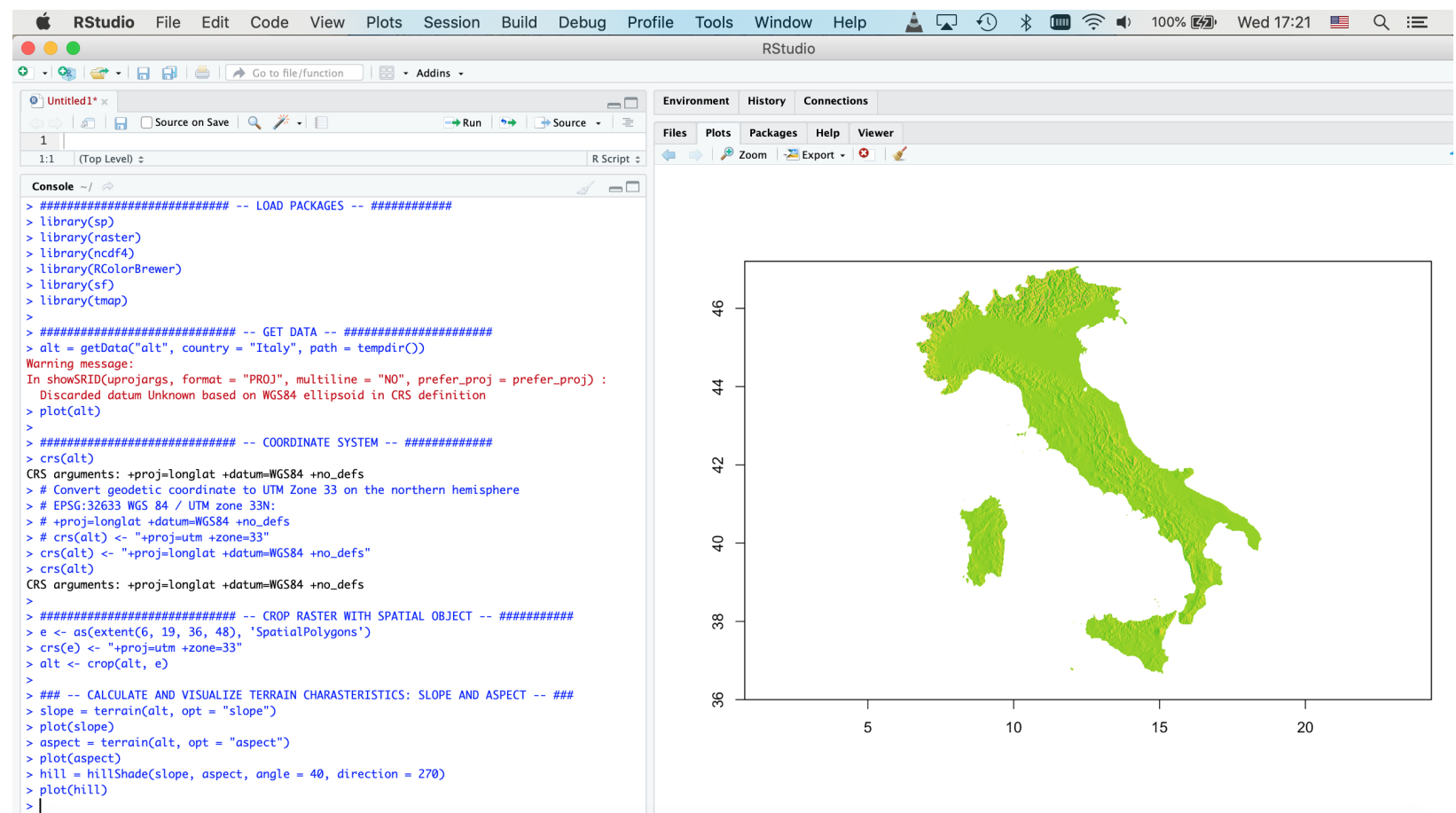

Figure 1. RStudio menu showing the script (left) and the resulting map (right).

The code shows following algorithms: 1) loading libraries; 2)getting data; 3) set up of coordinate system; 4) crop raster with spatial extent; 5) computing slope, aspect and hillshade of the terrain relief of Italy; 6) plotting the hillshade based on DEM SRTM90.

\section{Materials and methods}

There are a wide variety of packages in $\mathrm{R}$ language used for graphical plotting. This research uses the packages 'ggmap', 'maps', 'mapdata', 'sp', 'raster', 'tmap' for data capture, processing and cartographic visualization (Figure 1). Using these packages $\mathrm{R}$ demonstrates the functionality of traditional GIS software, briefly described below.

\section{Data capture and preprocessing}

The raster DEM grid covering Italy, the Apennine Peninsula was visualized and modeled using R graphical functionality (Murrell, 2005). Specifically, following cartographic packages were applied: 'tmap', 'raster', 'ggmap' and 'map- 
data', supported by the auxiliary packages ('sp', 'sf', 'ggplot2'). The data processing started by defining input spatial data and capture: alt = getData("alt", country $=$ "Italy", path $=$ tempdir()).

The collected data were pre-processed before they were used as an input data in R. Thus, when the data were loaded, the extent (dimensions) of the tabular data was checked up, as well as the column content: dim(italy). Since the table is rather big-sized, the initial and end part of the tables were inspected using the following functions: head(italy) and tail(italy), respectively. Then the data were inspected for their coordinate projection: crs(alt).

Afterwards, the common geographical projection (lon/lat) was defined using the following code: crs(alt) <- "+proj=longlat +datum=WGS84 +no_defs". If necessary for the students to experiment with projections, the variety of the projections can be set up using this function. For instance, converting geodetic coordinate to UTM Zone 33 on the northern hemisphere (EPSG:32633 WGS 84/UTM zone 33N) can be done using following code: $\mathrm{crs}(\mathrm{alt})<-$ " + proj=utm +zone $=33$ ". Afterwards, the spatial extent of the data was defined using the following code: e <- as(extent $(6,19,36,48)$, 'SpatialPolygons'). Here the West-EastSouth-North system is defined as the borders fo the study area (Figure 2).

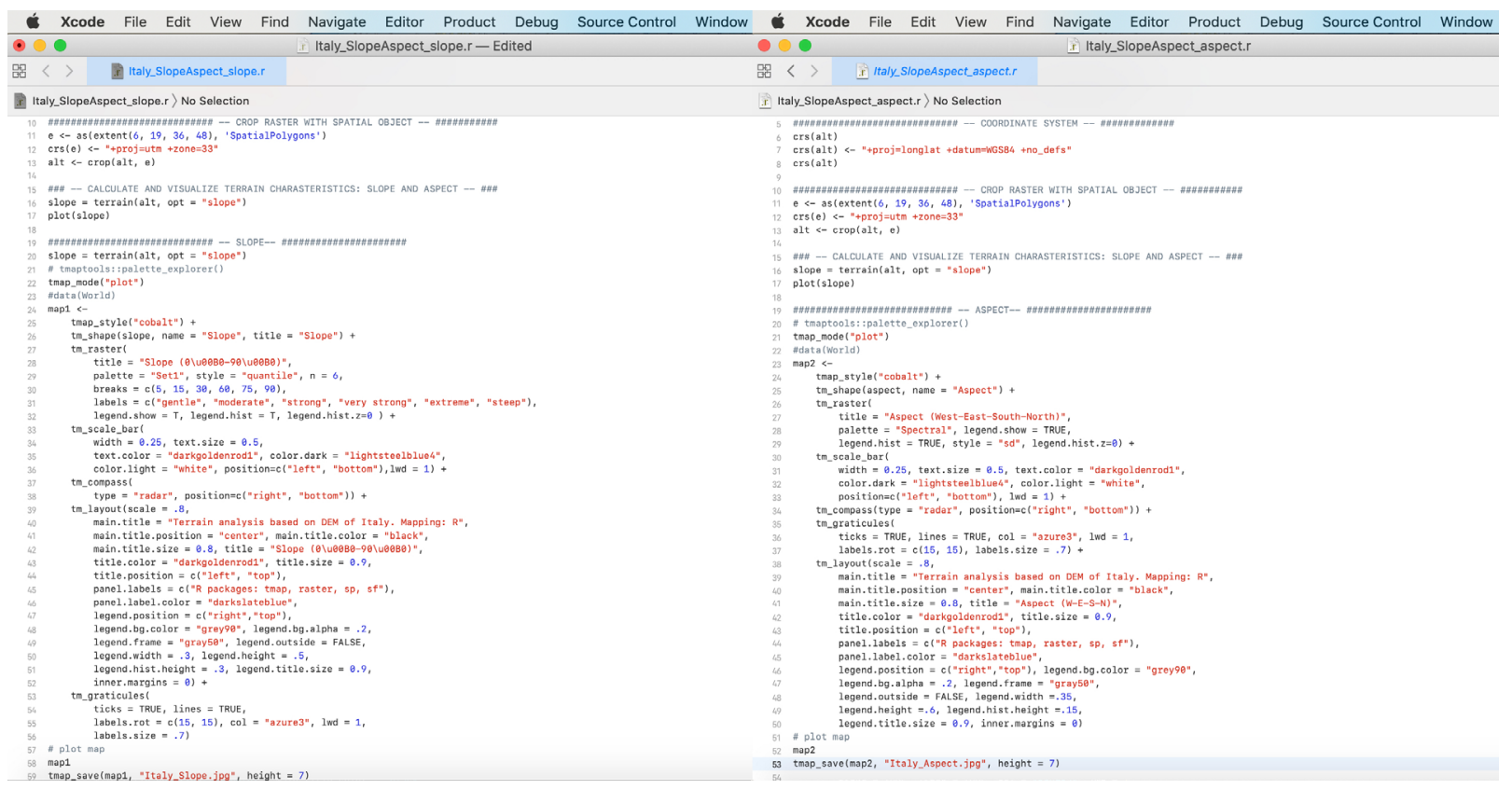

Figure 2. R scripts used for mapping slope and aspect for geomorphological modelling. 
The digital elevation models (DEM) obtained from the Shuttle Radar Topography Mission (SRTM) create perfect dataset for geomorphological studies due to the open availability and high resolution of the grid. There are various examples of using the SRTM data in geospatial research (Drăgut \& Eisank, 2012; Hirt, 2018) with discussed reliability (Frey \& Paul, 2012). The SRTM data sources present a reliable and accurate topographic dataset to gather reliable information about the relief terrain, taking into account the elevation values. The spatial SRTM DEM used in this research have $90 \mathrm{~m}^{*} 90 \mathrm{~m}$ resolution.

\section{Calculate terrain characteristics: slope and aspect}

A complex geomorphic analysis may include computation of indices such as mountain front of water divide sinuosity, asymmetry, drainage basin elongation, relief ratio, hypsometry, normalized steepness, and concavity, integrated with geomorphological analysis (Giano et al., 2018). This study presents the most important geomorphic features that are often included in geographic education curriculum and also embedded in R algorithms: computation and mapping of slope steepness, aspect orientation, visualization hillshade and DEM elevation. The slope stability analysis is based on calculating the slope steepness often applied in studies on geologic hazard risks, such as assessment of landslides in mountains, rock avalanches (Antonielli et al. 2020; Lemenkova et al. 2012).

Calculating slope, aspect and hillshade is based using existing slope and aspect generation mathematical algorithms (Ritter, 1987) of geomorphological models. Other computational examples of the terrain include, for instance, landscape metrics, used in environmental and sustainability studies assessing the vulnerability and ecological significance of the landscapes (Klaučo et al. 2014, 2017). In R, the calculation of slope and aspect maps was done using the following codes: slope $=$ terrain $($ alt, opt $=$ "slope" $)$ and aspect $=$ terrain $($ alt, opt $=$ "aspect"), respectively (Figure 2).

After the slope and aspect were computed using the scripts presented in Figure 2, the preliminary visualization without cartographic elements was done using the plot(slope) and plot(aspect) functions, respectively. Afterwards, the response of $\mathrm{R}$ for calculated slope and aspect unit analysis was translated to the 'tmap' package as the spatial input data where the additional cartographic elements were added on the maps (graticule, grids, annotations, title, subtitle, legend, etc) using multiple specially designed functions, as follows: tm_scale_bar, tm_compass, tm_raster, tm_layout, tm_graticules. The full script used for plotting the maps of slope and aspect is visualized in Figure 2. The overlay of these cartographic elements, slope and aspect maps, their legend and histograms of data distribution was performed after the slope and aspect maps were prepared based on the SRTM DEM data of Italy. The final maps are presented in Figure 3 (left: slope, right: aspect) and Figure 4 (left: hillshade, right: elevation). 

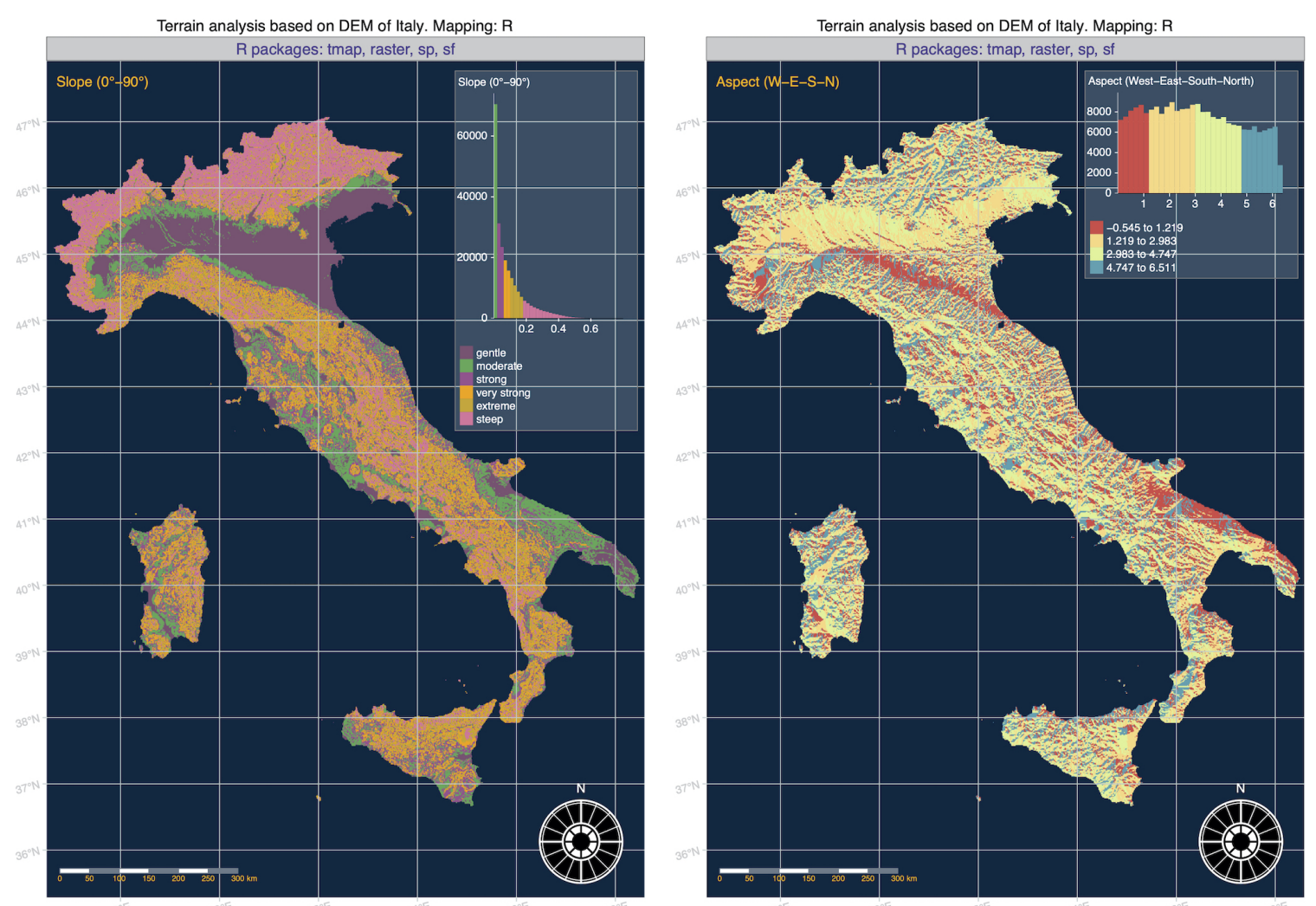

Figure 3. Map of slope (left) and aspect (right) plotted in $R$ using scripts presented in Figure 2.

Visualizing topographic maps: elevation and hillshade

The elevation DEM data of SRTM was used to create a hillshade map. The raster package provides an easy access to the SRTM $90 \mathrm{~m}$ resolution elevation data with the getData() function. For example, it is possible to download the elevation data for the whole country using the getData() function. The hillshade map shows the topographical shape of highs, hills and mountains using levels of gray on a map. The role of this kind of maps is to display relative slopes, though not in absolute heights. However, despite its relative estimation of the topography, the value of the shaded relief maps consists in its approach: they give the student an immediate appreciation for the surface topography, because a hillshade map helps to visually estimate the depths (Horn, 1981).

The hillshade map was created based on the terrain characteristics using the 'raster' package and then visualized as classic map with elements using 'tmap' 

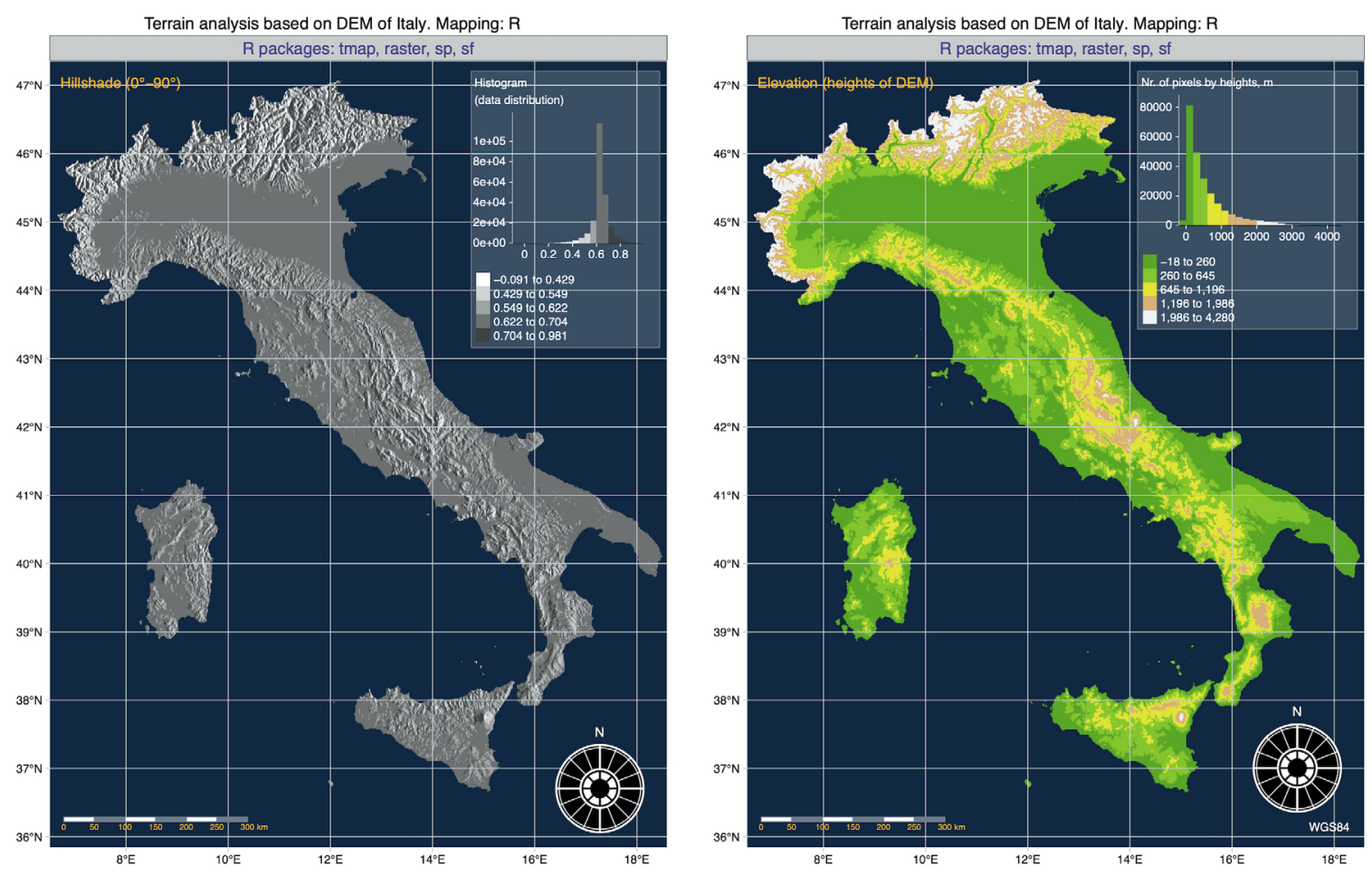

Figure 4. Map of hillshade in monochrome colors (left) and elevation map in terrain colors (right), plotted in $R$.

package. Thus, initially, the hillshade was calculated based on the input data from the previous research steps: slope and aspect using algorithms of hillshade computing (Jones, 1998). Both of them were calculated using 'raster package' with the terrain function. Computing of a hillshade was done by the hillShade() function using the following code: hill $=$ hillShade(slope, aspect, angle $=40$, direction $=270$ ). Now the hillshade was computed using slope and aspect of the terrain with the option argument set to "slope" or "aspect", respectively.

The previously created slope and aspect objects were used as input data and two new arguments - angle as $40^{\circ}$ (the elevation angle of the light source) and direction as $270^{\circ}$ (he direction (azimuth) angle of the light source (sun)) - were set up. The output hillshade map was plotted using plot(hill) function. Once the hillshade was computed, it was transferred to the 'tmap' package for further cartographic plotting. Here the visualizing was done using stacking of data layers similar to the traditional overlay in GIS, with the layer of the hillshade object (hill) colored using grey hues. 


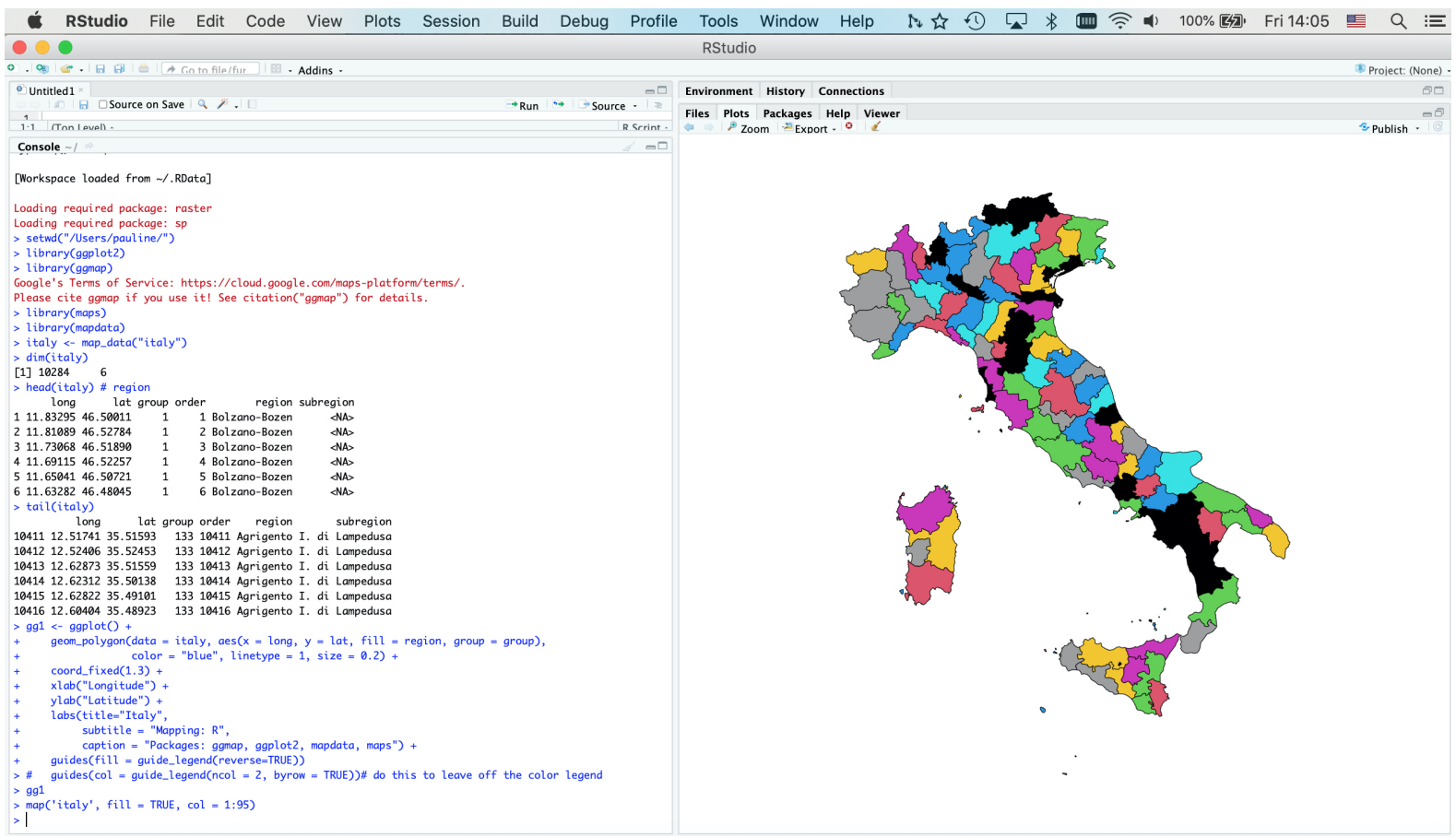

Figure 5. RStudio menu used for mapping regions of Italy using packages 'ggplot2', 'ggmap', 'maps' and 'mapdata'.

Script used for visualization (left) and resulting output map (right).

\section{Mapping regional division}

The advantages of the 'ggmap' package consists in the convenient mapping and plotting the regional map of Italy (Figure 5 and Figure 6). The maps package contains the outlines of Italy as country that have been with $\mathrm{R}$ as embedded data. The 'mapdata' package was used, since it has a higher-resolution vector outlines. The 'maps' package was used for its plotting functionality in addition to the 'ggplot2 package which operates on data frames (Wickham, 2009). Therefore the data from the 'maps' package were forwarded into a data.frame format of the 'ggplot' package (Figure 5, left).

The country data (Italy) and SRTM data (DEM) were also collected and loaded to RStudeio using common R syntax (Bivand et al. 2008). The country data on Italy origins from the NUTS III (Tertiary Administrative Units of the European Community) database of the United Nations Environment Program (UNEP) GRID-Geneva datasets made in 1989 (Becker \& Wilks, 1995). 


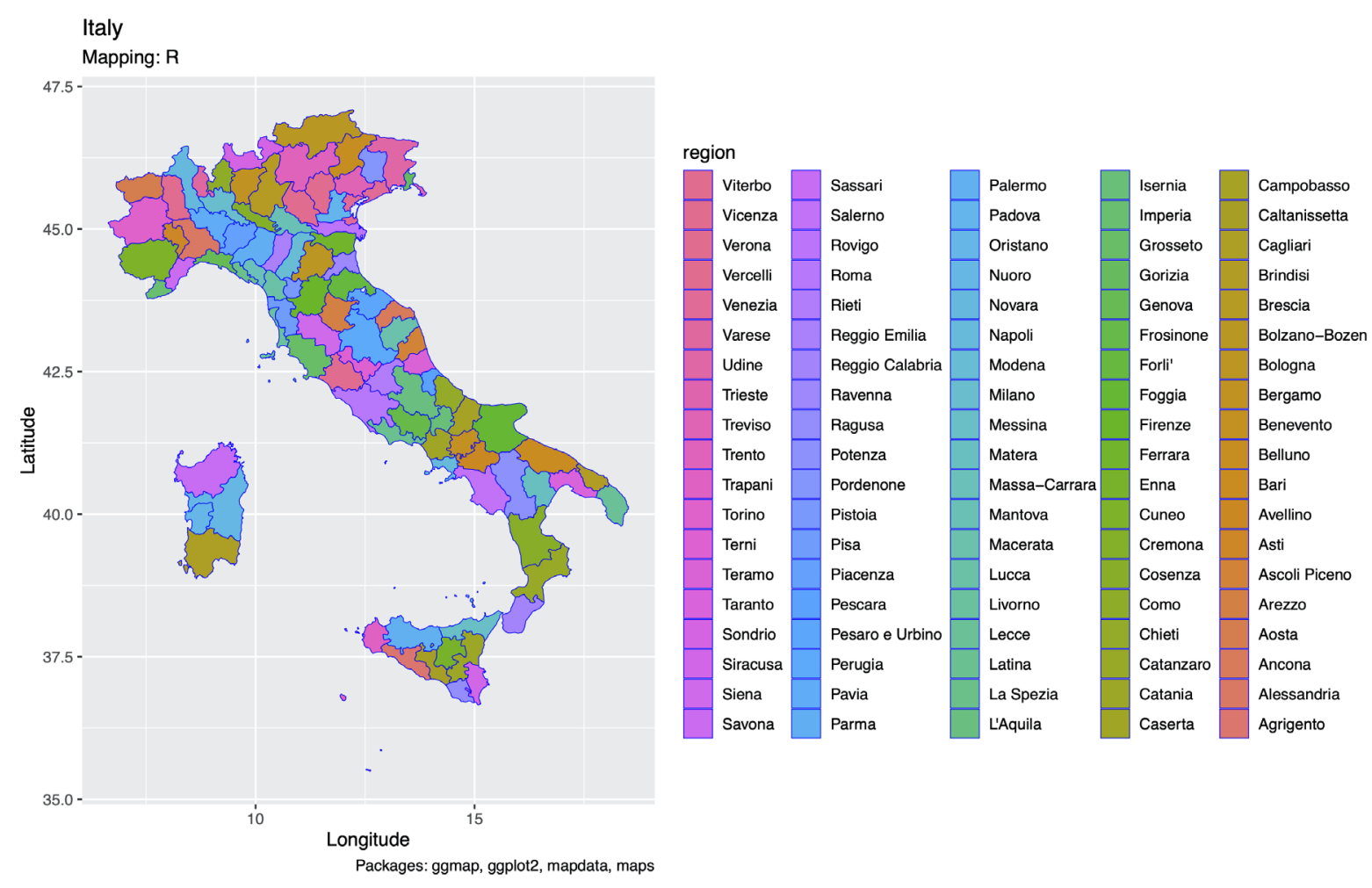

Figure 6. Map of Italy with subdivision by regions (left) and detailed color legend (right).

The function 'tm_shape' of library 'tmap' was applied for the creation of cartographic layout and then saved in jpg format using R. The 'tmap' library defines the shape objects plotted on a map (Tennekes, 2018) and visualized in Figure 6 . The base graphics of $\mathrm{R}$ was head directly to ggplot2 package. The 'ggplot2' package was used as a wrapper for the raster map visualization, enabling the finer operation with spatial objects. Using some functions of ggplot2 enables easier interaction with the data in $\mathrm{R}$ 'maps' package. Here the main map was plotted using geom_polygon function (geom_polygon(data $=$ italy, aes $(x=$ long, $\mathrm{y}=$ lat, group $=$ group) $)$, and aesthetics was added using additional elements of ggplot2 syntax: fill $=$ "pink", color $=$ "blue", linetype $=1$, size $=0.2$ ).

The annotations of the $\mathrm{XY}$ axes were made using the options xlab and ylab: $x l a b($ "Longitude") + ylab("Latitude"). The titles and the subtitles were also added on a mp using the following arguments of the 'ggplot2' package: labs(title="Italy", subtitle = "Mapping: R", caption = "Packages: ggmap, ggplot2, mapdata, maps"). The legend has been added on a map using the code: guides(fill 
= guide_legend(reverse=TRUE)). The disadvantage of the 'ggplot2', however that it does not support different cartographic projections. Once a map layout is prepared, the map was converted to the 'jpg' format and visualized in Figure 6.

\section{Results and discussion}

The visualized DEM derivatives included geomorphometric maps of slope, aspect and hillshade relief maps which shows the trends in the orientation (North-South-West-East) and slope steepness of the raster grids in different sub-regions of the Apennines. The slope directions of the rural areas of Italy revealed variations in the data showing 'gentle', 'moderate', 'strong', 'very strong', 'extreme' and 'steep' slopes of the mountainous regions of Italy. The number of pixels (over 75,000 on a raster grid) was the greatest in the 'moderate' slope level comparing to the others: 35,000 pixels for the 'gentle', 22,000 for 'strong', 18,000 for 'very strong', 11,000 for 'extreme' and 9,000 for 'extreme' slopes. As the influence of the geomorphological patterns was clear on the slope and aspect maps correlating with a general elevation map layer, detecting geomorphometric trends shows effective results by the presented and used $R$ packages.

The trends in aspect data distribution in the Apennines visualized using $\mathrm{R}$ package 'tmap' apparently reflect the structure of the geomorphological patterns of the study area. When comparing the four major classes of the slopes orientation (West-North-East-South) with the subdivided (North-West, NorthEast, South-West, South-East) in Figure 3, the integrated dataset shows four classes: $1^{\text {st }}$ class (East, colored red), the $2^{\text {nd }}$ class (West, colored orange) $3^{\text {rd }}$ class (South, colored yellow) and the $4^{\text {th }}$ class (North, colored blue). The data assessment demonstrated the subdivision of the slopes by DEM. The visualized elevation map of the Apennines identified heights in meters grouped in five major classes (Figure 4 ) and colored by terrain.colors palette of R. The classes include heights from 0 to 4,000 meters. Additionally, a hillshade map was visualized as a raster calculation based on slope and aspect layers (Figure 4).

The applied parameters of $\mathrm{R}$ libraries were sufficient for the terrain mapping and geomorphological analysis, as presented in this work, and therefore, $\mathrm{R}$ can be strongly recommended in similar research studies. All maps presented in this article are made and plotted in R. Although there are special cartographic toolsets and software has functionality for the complex cartographic workflow using scripting approaches e.g. GRASS GIS or GMT (Lemenkova, 2020e, 2020f), the direct use of $R$ language presents the principally next steps in the development of the cartographic methods, since using programming language is completely based on the machine learning algorithms for data evaluation, which could be effectively used for geoinformatics and mapping. 


\section{Conclusions}

Automatization in topographic modelling is largely presented by the use of scripting languages (Lemenkova, 2019b, 2019c, 2019d) or specially designed software that uses approaches of machine learning in geoinformatics (Gauger et al. 2007; Iwahashi \& Pike, 2007; Schenke \& Lemenkova, 2008; Alvioli et al. 2016; Kuhn et al. 2007). Both practical and theoretical conceptual approaches are the core issues of the GIS-based geomorphic mapping. Therefore, the advances in $\mathrm{R}$ programming and development of its new libraries present new ways in geographic education by rapidly evolving scripting technologies used in cartographic visualization. The extended possibilities of R can successfully support and top up the existing GIS methods. Besides, free and open source R language is available for every student, which makes it especially useful in geographic education due to its availability and functionality.

However, nowadays, the applications of $\mathrm{R}$ are mostly presented in cases of the statistical analysis (Lemenkova, 2018, 2020g), while the use of its cartographic packages for geographic visualization have not yet been adequately addressed. This paper aims to fill in this lacuna and to present the illustration of how R libraries designed for cartographic needs can be used in classes of geography by the students for geomorphological analysis with a case study of Italy, known for the diverse relief patterns (mountains, slopes, hills, plains, highs). Mapping approaches by R presented in this research demonstrated maps of the terrain analysis based on DEM of the Apennines.

The value of using $\mathrm{R}$ in geosciences consists in practical reproducibility of scripts in geography and geosciences. Therefore, the use of $\mathrm{R}$ in geographic education is a highly promising approach. However, there are some possible drawbacks and disadvantages comparing to the traditional GIS, which should be mentioned as well. Thus, the syntax of $\mathrm{R}$ may not always easily accessible by the beginner students and require preliminary skills in coding. Second, the presented packages require installation. Third, some concepts of R may not be always straightforward for the students and require additional classes and special teaching on script approaches. Fourth, the plotting of maps always require some familiarity with general GIS concepts, such as projections, plotting, operating with spatial data, etc. 


\section{References}

Allen, J., Brandte, U., Brauer, A., Hubbertens, H.-W., Huntley, B., Keller, J., Kraml, M., Mackensen, A., Mingram, J., Negendank, J., Nowaczyk, N., Oberhansli, H., Watts, W., Wulf, S., \& Zolitschka, B. (1999). Rapid environmental changes in southern Europe during the last glacial period. Nature, 400, 740-743.

Allevato, E., Saulino, L., Cesarano, G., Chirico, G.B., D'Urso, G., Bolognesi, S.F., Rita, A., Rossi, S., Saracino, A., \& Bonanomi, G. (2019). Canopy damage by spring frost in European beech along the Apennines: effect of latitude, altitude and aspect. Remote Sensing of Environment, 225, 431-440.

Alvioli, M., Guzzetti, F., \& Marchesini, I. (2020). Parameter-free delineation of slope units and terrain subdivision of Italy. Geomorphology, 358, 107124.

Alvioli, M., Marchesini, I., Reichenbach, P., Rossi, M., Ardizzone, F., Fiorucci, F., \& Guzzetti, F. (2016). Automatic delineation of geomorphological slope units with r.slopeunits v1.0 and their optimization for land-slide susceptibility modeling. Geoscientific Model Development, 812 (9), 3975-3991.

Antonielli, B., Della Seta, M., Esposito, C., Mugnozza, G.S., Schilirò, L., Spadi, M., \& Tallini, M. (2020). Quaternary rock avalanches in the Apennines: New data and interpretation of the huge clastic deposit of the L'Aquila Basin (central Italy). Geomorphology, 361, 107194.

Ascione, A., Cinque, A., Miccadei, E., Villani, F., \& Berti, C. (2008). The Plio-Quaternary uplift of the Apennine chain: new data from the analysis of topography and river valleys in Central Italy. Geomorphology, 102, 105-118.

Bartolini, C., D'Agostino, N., \& Dramis, F. (2003). Topography, exhumation, and drainage network evolution of the Apennines. Episodes 26, 212-216.

Bartolini, C. (2003). When did the Northern Apennine become a mountain chain? Quaternary International, 101-102, 75-80.

Becker, R.A., Wilks, A.R., Brownrigg, R., \& Minka, T.P. maps: Draw Geographical Maps, 2013. URL http:/ /CRAN.R-project.org/package=maps R package version 2.3-2.

Becker, R.A., \& Wilks, A.R. 1995. Constructing a Geographical Database. AT\&T Bell Laboratories Statistics Research Report [95.2].

Bertotti, G., Capozzi, R., \& Picotti, V. (1997). Extension controls Quaternary tectonics, geomorphology and sedimentation of the N-Apennines foothills and adjacent Po Plain (Italy). Tectonophysics, 282, 291-301.

Bivand, R.S., Pebesma, E.J., \& Gómez-Rubio, V. (2008). Applied Spatial Data Analysis with R. New York: Springer-Verlag.

Brewer, C.A., Hatchard, G.W., \& Harrower, M.A. (2003). ColorBrewer in Print: A Catalog of Color Schemes for Maps. Cartography and Geographic Information Science, 30(1), 5-32. 
Bull, W.B. (2007). Tectonic Geomorphology of Mountains: A New Approach to Paleoseismology. Blackwell Publishing, Oxford, UK, 328 pp. ISBN: 978-1-40515479-6.

Centamore, E., \& Nisio, S. (2003). Effects of uplift and tilting in the Central-Northern Apennines (Italy). Quaternary International, 102, 93-101.

Cosentino, D., Asti, R., Nocentini, M., Gliozzi, E., Kotsakis, T., Mattei, M., Esu, D., Spadi, M., Tallini, M., Cifelli, F., Pennacchioni, M., Cavuoto, G., \& Di Fiore, V. (2017). New insights into the onset and subsequent evolution of the central Apennine extensional intermontane basins based on the tectonically active L'Aquila Basin (central Italy). Geological Society of America Bulletin, 129(9-10), 1314-1336.

Da Serra Costa, F., Machado Damâzio J., Pereira Das Neves, F., \& Rodrigues Simabuguro, M.F. (1996). Linking a synthetic storm generation model with the IDRISI GIS. HydroGIS96: Application of Geographic Information Systems in Hydrology and Water Resources Management (Proceedings of the Vienna Conference, April 1996). IAHS Publ., 235, 107-113.

Drăgut, L., \& Eisank, C. (2012). Automated object-based classification of topography from SRTM data. Geomorphology, 141-142, 21-33.

Evans, I.S. (2012). Geomorphometry and landform mapping: what is a landform? Geomorphology, 137, 94-106.

Frey, H., \& Paul, F. (2012). On the suitability of the SRTM DEM and ASTER GDEM for the compilation of topographic parameters in glacier inventories. International Journal of Applied Earth Observation and Geoinformation, 18, 480-490.

Gauger, S., Kuhn, G., Gohl, K., Feigl, T., Lemenkova, P., \& Hillenbrand, C. (2007). Swathbathymetric mapping. Reports on Polar and Marine Research, 557, 38-45.

Gemelli, A., Mancini, A., \& Longhi, S. (2011). GIS-based energy-economic model of low temperature geothermal resources: A case study in the Italian Marche region. Renewable Energy, 36(9), 2474-2483.

Geurts, A.H., Whittaker, A.C., Gawthorpe, R.L., \& Cowie, P.A. (2020). Transient landscape and stratigraphic responses to drainage integration in the actively extending central Italian Apennines. Geomorphology, 353, 107013.

Giano, S.I., Pescatore, E., Agosta, F., \& Prosser, G. (2018). Geomorphic evidence of Quaternary tectonics within an underlap fault zone of southern Apennines, Italy. Geomorphology, 303, 172-190.

Guido, M.A., Molinari, C., Moneta, V., Branch, N., Black, S., Simmonds, M., Stastney, P., \& Montanari, C. (2020) Climate and vegetation dynamics of the Northern Apennines (Italy) during the Late Pleistocene and Holocene. Quaternary Science Reviews, 231, 106206. https:// doi.org/10.1016/j.quascirev.2020.106206

Hirt, C. (2018). Artefact detection in global digital elevation models (DEMs): The Maximum Slope Approach and its application for complete screening of the SRTM v4.1 and MERIT DEMs. Remote Sensing of Environment, 207, 27-41. 
Hijmans, R.J. (2017). raster: Geographic Data Analysis and Modeling. R package version 2.6-7, URL https:/ /CRAN.R-project.org/ package=raster

Horn, B.K.P. (1981). Hill shading and the reflectance map. Proceedings of the IEEE, 69(1), 14-47.

Iwahashi, J., \& Pike, R.J. (2007). Automated classifications of topography from DEMs by an unsupervised nested-means algorithm and a three-part geometric signature. Geomorphology, 86, 409-440.

Jones, K.H. (1998). A comparison of algorithms used to compute hill slope as a property of the DEM. Computers \& Geosciences, 24, 315-323.

Kahle, D., \& Wickham, H. (2013). ggmap: Spatial Visualization with ggplot2. The $R$ Journal, 5(1), 144-161.

Klaučo, M., Gregorová, B., Stankov, U., Marković, V., \& Lemenkova, P. (2013a). Determination of ecological significance based on geostatistical assessment: a case study from the Slovak Natura 2000 protected area. Open Geosciences, 5(1), 28-42.

Klaučo, M., Gregorová, B., Stankov, U., Marković, V., \& Lemenkova, P. (2013b). Interpretation of Landscape Values, Typology and Quality Using Methods of Spatial Metrics for Ecological Planning. In Environmental and Climate Technologies, October 14, 2013. Riga, Latvia.

Klaučo, M., Gregorová, B., Stankov, U., Marković, V., \& Lemenkova, P. (2014). Landscape metrics as indicator for ecological significance: assessment of Sitno Natura 2000 sites, Slovakia. In Ecology and Environmental Protection, March 19-20, 2014, Minsk: BSU Press, 85-90.

Klaučo, M., Gregorová, B., Koleda, P., Stankov, U., Marković, V., \& Lemenkova, P. (2017). Land planning as a support for sustainable development based on tourism: A case study of Slovak Rural Region. Environmental Engineering and Management Journal, 2(16), 449-458.

Kuhn, G., Hass, C., Kober, M., Petitat, M., Feigl, T., Hillenbrand, C. D., Kruger, S., Forwick, M., Gauger, S., Lemenkova, P. (2006). The response of quaternary climatic cycles in the South-East Pacific: development of the opal belt and dynamics behavior of the West Antarctic ice sheet. In: Gohl, K. (ed). Expeditions programm Nr. 75 ANT XXIII/4, Alfred Wegener Institute Helmholtz Centre for Polar and Marine Research.

Lemenkova, P. (2020a). Using GMT for 2D and 3D Modeling of the Ryukyu Trench Topography, Pacific Ocean. Miscellanea Geographica, 25(3), 1-13.

Lemenkova, P. (2020b). The geomorphology of the Makran Trench in the context of the geological and geophysical settings of the Arabian Sea. Geology, Geophysics and Environment, 46(3), 205-222.

Lemenkova, P. (2020c). NOAA Marine Geophysical Data and a GEBCO Grid for the Topographical Analysis of Japanese Archipelago by Means of GRASS GIS and GDAL Library. Geomatics and Environmental Engineering, 14(4), 25-45. 
Lemenkova, P. (2020d). SAGA GIS for information extraction on presence and conditions of vegetation of northern coast of Iceland based on the Landsat TM. Acta Biologica Marisiensis, 3(2), 10-21. https://doi.org/10.2478/abmj-2020-0007

Lemenkova, P. (2020e). GEBCO Gridded Bathymetric Datasets for Mapping Japan Trench Geomorphology by Means of GMT Scripting Toolset. Geodesy and Cartography, 46 (3), 98-112.

Lemenkova, P. (2020f). Fractal surfaces of synthetical DEM generated by GRASS GIS module r.surf.fractal from ETOPO1 raster grid. Journal of Geodesy and Geoinformation, 7(1), 86-102.

Lemenkova, P. (2020g), R Libraries \{dendextend\} and \{magrittr\} and Clustering Package scipy.cluster of Python For Modelling Diagrams of Dendrogram Trees. Carpathian Journal of Electronic and Computer Engineering, 13(1), 5-12.

Lemenkova, P. (2019a). Statistical Analysis of the Mariana Trench Geomorphology Using R Programming Language. Geodesy and Cartography, 45(2), 57-84.

Lemenkova, P. (2019b), Topographic surface modelling using raster grid datasets by GMT: example of the Kuril-Kamchatka Trench, Pacific Ocean. Reports on Geodesy and Geoinformatics, 108, 9-22.

Lemenkova, P. (2019c). AWK and GNU Octave Programming Languages Integrated with Generic Mapping Tools for Geomorphological Analysis. GeoScience Engineering, 65 (4), 1-22.

Lemenkova, P. (2019d). Testing Linear Regressions by StatsModel Library of Python for Oceanological Data Interpretation. Aquatic Sciences and Engineering, 34, 51-60.

Lemenkova, P. (2018). R scripting libraries for comparative analysis of the correlation methods to identify factors affecting Mariana Trench formation. Journal of Marine Technology and Environment, 2, 35-42.

Lemenkova, P. (2015). To the Question of the Environmental Education: how Landsat TM, ETM+ and MSS Images can be Processed by GIS-Techniques for Geospatial Research. Trends and Perspectives in the Creating Regional Systems of the Additional Adults Education. Vitebsk, Belarus.

Lemenkova, P. (2014). Opportunities for Classes of Geography in the High School: the Use of 'CORINE' Project Data, Satellite Images and IDRISI GIS for Geovisualization. In: Perspectives for the Development of Higher Education. Belarus, Grodno, 284-286.

Lemenkova, P. (2013). Monitoring Changes in Agricultural Landscapes of Central Europe, Hungary: Application of ILWIS GIS for Image Processing. In: Geoinformatics: Theoretical and Applied Aspects. Ukraine, Kiev, May 13-16.

Lemenkova, P., Promper, C. \& Glade, T. (2012). Economic Assessment of Landslide Risk for the Waidhofen a.d. Ybbs Region, Alpine Foreland, Lower Austria. In: Eberhardt, E., Froese, C., Turner, A. K. \& Leroueil, S. (Eds.). Protecting Society through Improved Understanding. $11^{\text {th }}$ International Symposium on Landslides \& the $2^{\text {nd }}$ North American Symposium on Landslides \& Engineered Slopes (NASL), June 2-8, 2012. Canada, Banff, 279-285. 
Lemenkova, P. (2011). Seagrass Mapping and Monitoring Along the Coasts of Crete, Greece. M.Sc. Thesis. Netherlands: University of Twente. 158 pp.

Murrell, P. (2005). R Graphics. Chapman \& Hall/CRC Press.

Neuwirth E. (2014). RColorBrewer: ColorBrewer Palettes. R package version 1.1-2, URL https://CRAN.R-project.org/package $=$ RColorBrewer

Pebesma, E. (2017). sf: Simple Features for R. R package version 0.4-1, URL https:// CRAN.R-project.org/ package $=$ sf

Pike, R.J., Acevedo, W., \& Card, D.H. (1989). Topographic grain automated from digital elevation models. Proceedings, Auto-Carto 9, ASPRS/ACSM Baltimore MD, 2-7 April 1989, 128-137.

R Core Team (2020). R: A language and environment for statistical computing. R Foundation for Statistical Computing, Vienna, Austria. URL: https://www.Rproject.org/ Richard A. Becker, and Allan R. Wilks, «Maps in S», ATET Bell Laboratories Statistics Research Report [93.2], 1993.

Ritter, P. (1987). A vector-based slope and aspect generation algorithm. Photogrammetric Engineering and Remote Sensing, 53, 1109-1111.

RStudio Team (2017). RStudio: Integrated Development Environment for R. RStudio, Inc., Boston, MA. URL https:/ /www.RStudio.com/

Roberts, G.P., \& Michetti, A.M. (2004). Spatial and temporal variations in growth rates along active normal fault systems: an example from Lazio-Abruzzo, central Italy. Journal of Structural Geology, 26, 339-376.

Schenke, H. W., E Lemenkova, P. (2008). Zur Frage der Meeresboden-Kartographie: Die Nutzung von AutoTrace Digitizer für die Vektorisierung der Bathymetrischen Daten in der Petschora-See. Hydrographische Nachrichten, 81, 16-21.

Suetova, I.A., Ushakova, L.A., \& Lemenkova, P. (2005). Geoinformation mapping of the Barents and Pechora Seas. Geography and Natural Resources, 4, 138-142.

Tarquini, S., Isola, I., Favalli, M., Mazzarini, F., Bisson, M., Pareschi, M.T., \& Boschi, E. (2007). TINITALY/01: a new Triangular Irregular Network of Italy. Annales Geophysicae, 50, 407-425.

Tennekes, M. 2018, tmap: Thematic Maps in R. Journal of Statistical Software, 84(6), 1-39.

Vacca, A., Loddo, S., Melis, M.T., Funedda, A., Puddu, R., Verona, M., Fanni, S., Fantola, F., Madrau, S., Marrone, V.A., Serra, G., Tore, C., Manca, D., Pasci, S., Puddu, M.R., \& Schirru, P. (2014). A GIS based method for soil mapping in Sardinia, Italy: A geomatic approach. Journal of Environmental Management, 138 87-96.

Wickham, H. (2009). ggplot2: Elegant Graphics for Data Analysis. Springer-Verlag.

Zuffetti, C., \& Bersezio, R. (2020). Morphostructural evidence of Late Quaternary tectonics at the Po Plain-Northern Apennines border (Lombardy, Italy). Geomorphology, 364, 107245. 